\title{
Psychiatric morbidity and subsequent divorce : a couple-level register-based study in Finland
}

\section{Metsä-Simola, Niina Susanna}

2018-08

Metsä-Simola , N S , Martikainen , P T \& Monden , C 2018 , ' Psychiatric morbidity and subsequent divorce : a couple-level register-based study in Finland ' , Social Psychiatry and pÿPsychiatric Epidemiology , vol. 53 , no. 8 , pp. 823 831 . https://doi.org/10.1007/s00127-018-1521-2

http://hdl.handle.net/10138/298848

https://doi.org/10.1007/s00127-018-1521-2

acceptedVersion

Downloaded from Helda, University of Helsinki institutional repository.

This is an electronic reprint of the original article.

This reprint may differ from the original in pagination and typographic detail.

Please cite the original version. 
1 PSYCHIATRIC MORBIDITY AND SUBSEQUENT DIVORCE: A COUPLE-LEVEL

2 REGISTER-BASED STUDY IN FINLAND

3 Metsä-Simola Niina ${ }^{1}$, Martikainen Pekka ${ }^{1} \&$ Monden Christiaan ${ }^{2}$

4

$5 \quad{ }^{1}$ Population Research Unit, Department of Social Research, University of Helsinki

$6 \quad{ }^{2}$ Department of Sociology \& Nuffield College, University of Oxford

7

8 Correspondence:

$9 \quad$ Niina Metsä-Simola

10 niina.metsa-simola@ helsinki.fi

11

12 University of Helsinki, Department of Social Research

13 P.O. Box 18

1400014 University of Helsinki

15 Finland

16

$17 \quad$ Tel. +358405158566

18

19

20 Acknowledgements:

21 The authors acknowledge the support of the Academy of Finland and the Signe and Ane Gyllenberg

22 Foundation, and are grateful to Statistics Finland, National Institute of Health and Welfare, and the

23 Social Insurance Institution for permission to use the data. 


\section{ABSTRACT}

2 Purpose. Studies that assess the role of mental health for the risk of divorce are scarce and mostly rely

3 on individual-level data, although divorce is a couple-level phenomenon. Using data on couples, we

4 examine the effects of both spouses' psychiatric morbidity on the risk of divorce, and whether socio-

5 demographic factors affect these associations.

6 Methods. We followed 96,222 Finnish married couples for six years using register-based data on both

7 spouses and their household. New incidence of psychiatric morbidity and subsequent divorce was

8 identified from dates of prescription medication purchases and hospital admissions, and dates of

9 registered divorce. Socio-demographic factors were measured annually for both spouses and their

10 household. The effect of incident psychiatric morbidity on divorce risk was analyzed using Cox

11 regression.

12 Results. Psychiatric morbidity in men increased the age-adjusted risk of divorce more than two-fold

13 and in women nearly two-fold. The risk of divorce was particularly pronounced immediately after

14 new incidence of psychiatric morbidity, before settling to a persistently high level. Psychiatric

15 morbidity in both spouses increased the risk of divorce almost three-fold. Adjustment for socio-

16 economic factors had little effect on these associations.

17 Conclusions. Psychiatric morbidity is a persistent risk factor of divorce. The risk is larger when both

18 spouses experience psychiatric morbidity compared to only one spouse. The findings are consistent

19 with the idea that poor relationship quality and dissatisfaction in couples suffering from mental health

20 problems have long-term consequences for marital stability. Treatment of psychiatric morbidity

21 should not focus only on the individual but on couple-level dynamics.

22 Keywords: Psychiatric morbidity; couples; divorce; marital status; Finland 


\section{INIRODUCTION}

2

3 The divorced experience worse mental health and higher levels of mental distress than the married [1-

4 8], which may either result from the adverse causal effects of divorce on mental health, or the

5 selective effects of individuals in poor mental health or with other factors detrimental to mental health

6 being more likely to divorce [2,9-11]. The causal effects may either relate to the stress of going

7 through divorce, or to the loss of protective factors associated with marriage $[9,10]$. These protective

8 factors are mainly resources at the household level, such as higher household income and better living

9 conditions, the loss of which may also contribute to the level of stress experienced during the divorce

10 process. Conversely, explanations based on direct selection postulate that poor mental health

11 precedes divorce. However, selection effects may also be indirect; some factors either at the individual or at the household level - such as prior alcohol abuse - increase the risk of both poor mental health and divorce. Both of these selective explanations are often also referred to as selection out of marriage $[2,12,13]$.

Previous research mostly views the adverse causal effects of divorce on mental health as the main explanatory mechanism $[11,14,15]$. However, more recent studies that examine changes in mental health before and after divorce using longitudinal data from the UK [2, 8], Canada [12] and Finland [16] lend support for both selection and causal effects, and in the US National Comorbidity Survey mental disorders are also significant predictors of subsequent divorce [13, 17]. These previous studies on mental health and marital transitions rely on individual-level data, although divorce always takes place in a couple. If the poor health of either partner in a couple increases the risk of divorce, we are likely to underestimate the effect health has on divorce risk when we have no information on the health status of the partner. That is because we fail to identify part of the couples in poor health if we only have access to health information on one of the partners. With individual-level data it is also impossible to analyze the joint effects of both partners poor mental health on divorce risk. characteristics as well as household level factors are equally likely to affect the association between psychiatric morbidity and divorce risk. 
1 Only a few studies have examined the effect of poor mental health on divorce risk using data from

2 both spouses $[18,19]$. In both these studies couples with one spouse experiencing mental distress had

3 lower divorce risk than couples with both spouses in distress, and higher divorce risk than couples

4 with no distress. However, in the Australian sample [18]the effect of both spouses experiencing

5 mental distress was additive, whereas in the Norwegian sample [19] the divorce risk for couples with

6 two spouses suffering from mental distress was lower than expected based on the main effects of each

7 spouse. The studies also reached contradictory conclusions on whether the effect of men's or

8 women's poor mental health on divorce risk is stronger.

9 Part of the mental distress experienced immediately before divorce is likely to be attributable to

10 marital conflict and the process of going through divorce $[2,8,16]$, and thus estimates on the effect of

11 mental distress on divorce risk do not accurately reflect causal effects when the time from distress to

12 divorce is short $[13,18]$. Some studies have tried to overcome this by measuring mental distress up to

13 eight years before divorce [19], while others differentiate between lifetime mental disorders and those

14 with onset between survey waves [17]. As expected, estimates of the effect of psychiatric morbidity on divorce risk are larger when the time gap between disorder incidence and divorce is shorter [17,

16 19]. However, evidence on the timeline for the effects of poor mental health on divorce risk remain

17 vague and it is not clear whether the risk of divorce settles to a permanently higher level at some point 18 after disease incidence.

19 Our aim is to contribute to previous literature by analyzing how psychiatric morbidity predicts the probability of divorce at the couple-level. We first examine how the risk of divorce changes when time since incidence of psychiatric morbidity is taken into account, and whether these changes are similar for psychiatric morbidity in men and women. We then analyze if couples with both spouses experiencing psychiatric morbidity have higher risk of divorce than couples with only one spouse affected, and whether these effects depend on socio-demographic characteristics of both spouses. Instead of survey data, our analyses rely on a unique longitudinal data set that combines information from nationally representative administrative registers for both partners. The sample does not suffers from attrition or misreporting bias, and includes the exact dates of union formation and dissolution, all 
1 purchases of prescribed psychotropic medication, prescription reimbursement rights related to

2 psychosis, and hospital admissions with psychiatric diagnoses.

\section{METHODS}

4

5 We use register-based data on Finnish couples. The sample is derived from a two-stage random

6 sample. First, a simple random sample covering 14\% of individuals aged 40 or over and living in

7 private households at the end of 1997 was drawn from population registers. Second, all household

8 members of the selected individuals were added to the sample. We included all married couples with

9 both spouses aged 40 to 64 . The register-based data from Statistics Finland include dates of divorce

10 from 1998 to 2003, annual socio-demographic information from 1995 to 2003, and mortality follow-

11 up until the end of year 2003. These data were further linked to hospital records, reimbursement for

12 drug costs, and purchases of prescription medication from 1995 to 2003. The information on

13 hospitalizations is provided by the National Institute of Health and Welfare, and information on

14 medication purchases and reimbursement by the Social Insurance Institution. The data linkage was

15 done by Statistics Finland using personal identification codes (the Ethics Committee of Statistics

16 Finland's permission TK-53-373-09).

17 Psychiatric morbidity was defined as purchasing psycholeptics (ATC-codes N05) or psychoanaleptics

18 (N06, excluding anti-dementia drugs N06D), qualifying for special refund right for psychosis, or

19 being hospitalized with a psychiatric diagnosis (ICD-10 codes F20-F69, F99). We also measured age,

20 educational level, social class and main activity for both the male and the female partner. Educational

21 level was based on highest educational qualification held and classified as tertiary, intermediate, and

22 basic education or less. Social class was based on current occupation, or previous occupation if

23 currently economically inactive, and classified as upper non-manual, lower non-manual, manual and

24 other (e.g. farmers and other entrepreneurs). Main activity was based on labor market participation

25 during the last 12 months and classified as employed, unemployed, retired (mostly due to disability),

26 and other (e.g. house-wives and students).). Couple-level characteristics were measured with

27 household income, housing tenure, whether the household had resident children that were younger 
1 than 18 years, and union duration (less than 5 years, 5 to 9 years, and 10 years or more). Household

2 income included all taxable income sources for all household members, was divided with the number

3 of household consumption units corresponding to the OECD equivalence scale [20] and classified

4 into quintiles at the household level. For housing tenure, owner-occupiers were separated from others.

5 Design, participants and statistical analyses

6

7 For the purposes of these analyses we set the baseline at 1.1.1998. We first assessed baseline

8 psychiatric morbidity for all couples — that is, for both spouses - using hospital records and

9 information on prescription medication from the years 1996 and 1997. After excluding couples with

10 baseline psychiatric morbidity, the remaining 96,222 couples were followed for new incidence of

11 psychiatric morbidity and subsequent divorce from January 1, 1998 until December 31, 2003. Divorce

12 refers to the date when either partner moves out of the common household.

13 We used Cox proportional hazards regression models to analyze how psychiatric morbidity is related

14 to the risk of divorce. The outcome variable was the time from the beginning of follow-up (January 1,

15 1998) until the date of divorce. Censoring occurred at death, bereavement, emigration or the end of

16 the follow-up (December 31, 2003). The results are presented as hazard ratios (HR). Stata software

17 was used for all the analyses.

18 We used psychiatric morbidity of both spouses as time-varying binary covariates, and analyzed both

19 individual-level effects of either the husband or the wife having psychiatric morbidity, and the couple-

20 level effects of both spouses experiencing psychiatric morbidity. The variable measuring psychiatric

21 morbidity of the husband was 0 at the beginning of the follow-up period and 1 after first incidence of

22 psychiatric morbidity. A similar variable was used for the wife's psychiatric morbidity. The

23 interaction of these two variables stands for both partner experiencing psychiatric morbidity.

24 When analyzing the effects of only one partner - either the husband or the wife - showing psychiatric morbidity, we divided time since incidence of psychiatric morbidity into categories: 0 to 6 months, 6 
1 beginning of follow-up until divorce as the outcome variable, and the categorical time since incidence

2 of psychiatric morbidity as a time-varying covariate [21]. Similar modelling strategy has been used

3 previously to study changes in the risk of institutionalization [22] and mortality [23] after marital

4 transitions. When analyzing the effects of both spouses with psychiatric morbidity, we used a lag of

5 six months in the date of psychiatric morbidity incidence. The longer the lag, the more confident we

6 can be on the temporal order of psychiatric morbidity and divorce, because the process of separation

7 might trigger psychiatric morbidity already before the actual date of divorce.

8 We first adjusted for the age of both the husband and the wife, both varying annually in time, and then

9 for several other individual-level and couple-level covariates. Education of both spouses was

10 measured at the end of year 1997, and social class at the end of year 1995. Time-varying main activity

11 of both spouses, household income, home-ownership, resident children, and union duration were

12 measured annually.

\section{RESULTS}

15 During the follow-up we observed 22,991 couples with new incidence of psychiatric morbidity. In

162,475 of these cases both spouses experienced psychiatric morbidity (Table 1). The number of

17 divorces in these marriages was 270. Psychiatric morbidity was more common among women than

18 men, so that in 12,849 couples only the wife experienced psychiatric morbidity, compared to 7,667

19 couples were it was the husband only. The corresponding numbers for divorce were 1,153 and 852,

20 respectively. The total number of divorces during follow-up was 7,932, and of these 5,657 occurred

21 for couples with no psychiatric morbidity.

$\langle$ Table 1>

The risk of divorce was particularly pronounced immediately after the incidence of psychiatric morbidity (Figure 1). After 12 months since the incidence the risk of divorce seemed to settle to a persistently higher level compared to couples with no psychiatric morbidity. The effect of men's 
1 morbidity on divorce risk was somewhat higher than the effect of women's morbidity at all times

2 since the incidence of morbidity.

3

4 Because the risk of divorce was particularly pronounced during the six months following new

<Figure 1> incidence of psychiatric morbidity, we used a lag of six months in the date of psychiatric morbidity incidence when comparing the effect of having two spouses with psychiatric morbidity instead of only one spouse (Table 2). Psychiatric morbidity among both spouses increased the subsequent risk of divorce almost three-fold (HR 2.98, 95\% CI=2.53-3.51) compared to couples with no psychiatric morbidity, whereas psychiatric morbidity of the husband increased the risk more than two-fold (HR $2.33,95 \% \mathrm{CI}=2.13-2.54)$ and psychiatric morbidity of the wife less than two-fold (HR $1.8495 \%$ $\mathrm{CI}=1.71-1.9)(\mathrm{p}<0.01$ for all between-group differences $)$. The effect of both spouses having psychiatric morbidity (HR $2.9895 \% \mathrm{CI}=2.53,3.51$ ) is less than expected based on the main effects of the husband's and the wife's morbidity alone $(2.33 \times 1.84=4.23)$.

\section{$<$ Table 2>}

Compared to the effect that other socio-economic and demographic factors had on the risk of divorce, the effect of psychiatric morbidity was considerable. Poor socio-economic resources - being nonemployed, having low income, and not owning a home - all increased the risk of divorce, but less than psychiatric morbidity. The risk of divorce was also considerably lower in unions of longer duration. Furthermore, the association between these socio-demographic factors and the risk of divorce remained nearly unchanged when the incidence of psychiatric morbidity was adjusted for, and the association between psychiatric morbidity and divorce risk was robust against simultaneous adjustment for all the other covariates.

Most couples with psychiatric morbidity were identified through psychotropic medication purchases, whereas hospitalizations with psychiatric diagnoses were much less common (Table 3). The association between psychiatric hospital care and divorce risk was somewhat stronger than the association between psychotropic medication and divorce risk. The effect of husband's morbidity was 
1 larger than the effect of wife's morbidity irrespective of the measure of psychiatric morbidity, and the

2 effect of having two spouses with psychiatric morbidity was less than expected based on the main

3 effects of the husband's and wife's morbidity for both hospitalizations and psychotropic medication

4 purchases.

$5 \quad\langle$ Table 3>

\section{DISCUSSION}

7

8 Among Finnish middle-aged couples, psychiatric morbidity is a strong determinant of subsequent

9 divorce with an approximately two-fold increase among couples with one affected spouse. Psychiatric

10 morbidity among both spouses increases the risk of divorce even further, but less than expected based

11 on the main effects of the husband's and the wife's morbidity alone. Morbidity of the husband

12 increases the risk of divorce somewhat more than morbidity of the wife. Adjustment for individual-

13 level and couple-level socio-demographic factors has little effect on these associations.

14 The risk of divorce is most pronounced immediately after the incidence of psychiatric morbidity. It is

15 likely that some part of this increased risk of divorce immediately after psychiatric morbidity simply

16 reflects the process of separation $[2,8,24,25]$. Previous estimates on the effect of psychiatric

17 morbidity on divorce risk are larger when the time gap between disorder incidence and divorce is

18 shorter [17, 19]. In Finland, levels of psychotropic medication use are highest immediately before

19 divorce, but medication prevalence is clearly elevated already five years before divorce, suggesting

20 selective effects [16]. Because psychiatric morbidity predicts the risk of divorce at all examined times

21 after the date of onset, and the risk seems to settle to a consistently higher level two years after the

22 first incidence (HR of about 1.9 for men's and 1.65 for women's morbidity),psychiatric morbidity

23 seems to increase the risk of divorce through persistent long-term strain.

24 Social exchange theory suggests that the probability of divorce increases when the factors binding the

25 partners together are weak, the attractiveness of the partner decreases, or other alternatives seem more

26 appealing than staying in the relationship [26]. The attractiveness of a partner may decline when he or 
1 she falls ill, and illness of either partner may also lead to increased divorce risk by causing economic

2 strain [27]. On the other hand, individuals in poor health may actually be more prone to stay in a

3 marriage, because of the expected health gains of being with a partner become more significant [28].

4 Poor mental health could also be associated with higher divorce risk simply because socio-economic

5 disadvantage increases both the risk of poor health [29, 30] and the risk of divorce[31, 32]. However,

6 in this study the association between psychiatric morbidity and divorce appears not confounded or

7 mediated by other individual-level or couple-level socio-demographic factors. The effect of

8 psychiatric morbidity on divorce risk is also considerable compared to other socio-demographic

9 determinants of divorce, and the effects of these social factors for divorce risk are also independent of

10 psychiatric morbidity. Thus the association between psychiatric morbidity and higher divorce risk

11 does not result from the simultaneously higher morbidity and higher divorce risk among those socio-

12 economically disadvantaged. We also analyzed interactive effects (results not shown) to see if the

13 association between psychiatric morbidity and divorce risk depends on socio-economic resources, and

14 found education, social class and income to have no statistically significant interactive effect. This

15 further supports our conclusion that psychiatric morbidity and socio-economic characteristics are fully

16 independent risk factors of divorce. Theoretically this implies that the mechanisms linking psychiatric

17 morbidity to increased risk of divorce are different from the mechanisms linking socio-economic

18 disadvantage to higher divorce risk. Thus the link from psychiatric morbidity to increased divorce risk

19 is rather explained by relationship quality and satisfaction than by economic hardship associated with

20 socioeconomic factors [26, 27], suggesting that support measures for married individuals with

21 psychiatric morbidity should also focus on couple-level dynamics.

22 The effect of husband's morbidity on divorce risk remains somewhat higher than the effect of wife's

23 morbidity at all times since the disorder incidence. Gender-specific effects may be driven by

24 differences in social and economic roles. Women are often thought to provide more social support,

25 control and care for their partners than men [33-35] suggesting that women might also be more likely

26 to be more instrumental when a couple is facing difficulties. Thus the risk of divorce could be

27 expected to be larger if the wife falls ill than if the husband does. On the other hand, women are 
1

suggested to benefit more from marriage by gaining access to their husbands' better economic resources [36-38] and psychiatric morbidity among men could thus lead to higher marital distress through pronounced economic losses. However, the Finnish welfare system may buffer and compensate some of the most severe economic consequences of falling ill. Nevertheless, even if socio-demographic factors seem to have very limited effect on the association between psychiatric morbidity and divorce risk, more detailed studies on the economic consequences of psychiatric morbidity and their related implications for marital quality are needed to better understand the gender difference we found.

Mental disorders are more common among women than men [39], and accordingly we identify higher levels of psychiatric morbidity among women than men in our data. There may be gender differences in the types of disorders, with some disorders having a stronger impact on divorce risk than others. Because we lack information on the actual diagnosis for which the medication has been prescribed for, we cannot accurately separate between disorder types. Prevalence studies show that the risk for psychotic disorders is similar among men and women [40], whereas mood and anxiety disorders are more common among women than men [39-42].

It is thus possible that women on average experience and are treated for less severe psychiatric conditions than men, which thus would have less consequences for marital satisfaction and stability. In previous research, mental distress measured with the Mental Health Inventory, presumed to indicate psychiatric morbidity, was more strongly related to divorce risk among men than women in an Australian sample of adults [18]. In contrast, in a Norwegian sample using the Global Mental Health measure, dichotomized so that mental distress prevalence corresponded to prevalence estimates for depression, the effect was larger among women than men [19]. This could imply that less severe mental distress increases the risk of divorce more among women than men, whereas more severe psychiatric morbidity increases the risk of divorce more among men. However, the effect of psychiatric morbidity on divorce risk remained stronger among men than among women regardless of 
1 how morbidity was measured. Both psychotropic drug use only, which is thought to reflect less severe

2 morbidity, as well as psychiatric hospitalizations, which mainly reflect more severe disorders are

3 more strongly related to divorce in men than women. Thus the consequences of both more and less

4 severe disorders on divorce risk appear to be somewhat stronger if they appear in men than in women.

5 The prevalence of alcohol use disorders is also higher among men than women [41, 42], and also the

6 comorbidity rates of mental disorders with alcohol use disorders may be higher among men than

7 women [41-43]. Because alcohol abuse is suggested to increase the probability of divorce [44, 45],

8 higher comorbidity could partly explain why the association of psychiatric morbidity and divorce is

9 larger among men. Future studies should explore in more detail gender differences in the associations

10 between different psychiatric disorders and divorce risk

11 The risk of divorce is clearly higher when both spouses experience psychiatric morbidity compared to 12 couples with only one affected spouse. Analyses using no lag and a 12-month lag in the date of psychiatric morbidity (not shown) confirmed the robustness of this result. However, having two

14 spouses with psychiatric morbidity does not multiply the risk of divorce, which would imply an 15 accumulation of disadvantage, but the effect is less than the additive combination of the individual-

16 level risks of the husband and the wife, supporting previous findings from Norway [19].

17 Nevertheless, it should be kept in mind that the husband's and the wife's mortality in a couple are

18 hardly independent of each other. In fact, psychiatric morbidity of one spouse is an important

19 predictor of morbidity of the other spouse [46]. It is thus inaccurate to expect that the effect of having two spouses with psychiatric morbidity on divorce risk could be derived directly from the main effects of the husband's and the wife's morbidity.

22 The health mismatch hypothesis suggests that the expected gains of remaining in the union decline for the healthy spouse when the other spouse is in poor health [26]. However, because couples with two spouses both experiencing psychiatric morbidity have higher risk of divorce than couples with only one affected spouse, it seems that psychiatric morbidity of the partner may encourage individuals to seek other alternatives even when they suffer psychiatric morbidity themselves. Although individuals

27 in poor health are suggested to expect health gains from having a partner and thus have a higher 
1 probability to remain married [28], these expectations might be lower when the partner is also ill, or

2 the declining attractiveness of the ill partner [26] could cancel out the expected benefits. However, if

3 the high risk of divorce was mainly a matter of finding better alternatives, then we would expect

4 psychiatric morbidity to have less effect on the risk of divorce when the other resources of the partner,

5 e.g. income, are higher. Instead socio-economic factors seem to have a very limited role in the

6 association between psychiatric morbidity and divorce risk. We thus suggest that psychiatric

7 morbidity among both partners further increases strain in the relationship compared to couples with

8 only one affected spouse, having stronger implications for relationship quality and marital

9 satisfaction.

10 Our measure of psychiatric morbidity is objective and based on clinical evaluation, but only captures

11 individuals who have been treated. While the social consequences of psychiatric morbidity may

12 depend on receiving treatment, our results clearly show that even if individuals with poor mental

13 health are treated, their risk of divorce is still elevated years after disorder incidence. Thus it is not

14 sufficient to focus only on treatment of the individual, but attention should be given on couple-level

15 dynamics.

17 Even if our study benefits from a large longitudinal data set with no recall bias or selective attrition, it

18 is not without limitations. Although we only included couples considered healthy at baseline,

19 individuals may have already had past episodes of treatment, because mental disorders are usually

20 first diagnosed at a younger age, and our sample only included couples aged 40 to 64 . The association

21 between psychiatric morbidity and divorce risk may also be different in other age groups. Among

22 older individuals divorce is less common, whereas psychotropic medication is more common. Of

23 Finns aged 65 or over, $25 \%$ use psychotropic medication [47], and up to $40 \%$ of those aged 75 or over

24 do so [48]. Nevertheless, adding couples aged 65 to 74 to our sample did not have a statistically

25 significant effect on the age-adjusted associations between psychiatric morbidity and divorce risk. The

26 older age of the couples in this study also means that the average duration of unions is quite long. 
1 Psychiatric morbidity could have a larger effect in unions of younger Finns and of shorter duration.

2 Because couple-level data on younger couples were not available, we compared the effect of

3 psychiatric morbidity on divorce risk in different age-groups using individual-level register-data on

4 Finnish adults [16]. Among 40 to 64 year-olds the association between psychiatric morbidity and risk

5 of divorce was only 9\% larger than among 18 to 39 year-olds (results not shown). The association

6 between psychiatric disorders and divorce risk may also be different for non-married couples than for

7 married couples. We included only married couples, because non-marital cohabitation is not typical

8 among middle-aged Finns, and thus the number of cohabiters in our sample was small compared to

9 married couples. Additional analyses (results not shown) verified that including both married and

10 non-married couples had little effect on our results. We look forward to future studies that replicate

11 our analyses in other age groups and including both non-married and married couples.

12 There could also be differences in seeking treatment, particularly between men and women. However,

13 a previous Finnish study found no gender differences in the probability to treatment seeking among

14 depressed adults after disorder severity and perceived impairment were adjusted for [49]. There may

15 also be differences in how different types of disorders are associated with the risk of divorce, and the

16 combination of disorders within a couple may also matter. Unfortunately, our data only contained

17 information on type of medication and not the actual diagnosis it had been prescribed for. We

18 encourage future research to elaborate this topic, and to examine how different psychiatric disorders

19 are intertwined with marital quality, and how couples with psychiatric morbidity could be supported

20 to avoid adverse social consequences such as divorce. The reasons why husbands' morbidity increases

21 the risk of divorce more than wives' morbidity should also be explored further.

\section{Conflicts of interest}

25 On behalf of all authors, the corresponding author states that there is no conflict of interest. 


\section{References}

2 1. Afifi TO, Cox BJ, Enns MW (2006) Mental health profiles among married, nevermarried, and separated/divorced mothers in a nationally representative sample. Soc Psychiatry Psychiatr Epidemiol 41:122-129 . doi: 10.1007/s00127-005-0005-3

5 2. Blekesaune M (2008) Partnership Transitions and Mental Distress: Investigating Temporal Order. J Marriage Fam 70:879-890 . doi: 10.1111/j.17413737.2008.00533.x

8 3. Breslau J, Miller E, Jin R, et al (2011) A multinational study of mental disorders, marriage, and divorce. Acta Psychiatr Scand 124:474-486 . doi: 10.1111/j.16000447.2011.01712.x

4. Hughes ME, Waite LJ (2009) Marital Biography and Health at Mid-Life. J Health Soc Behav 50:344-358

5. Liu RX, Chen Z (2006) The Effects of Marital Conflict and Marital Disruption on Depressive Affect: A Comparison Between Women In and Out of Poverty*. Soc Sci Q 87:250-271 . doi: 10.1111/j.1540-6237.2006.00379.x

6. Meadows SO, McLanahan SS, Brooks-Gunn J (2008) Stability and Change in Family Structure and Maternal Health Trajectories. Am Sociol Rev 73:314-334 . doi: $10.1177 / 000312240807300207$

7. Strohschein L, McDonough P, Monette G, Shao Q (2005) Marital transitions and mental health: are there gender differences in the short-term effects of marital status change? Soc Sci Med 1982 61:2293-2303 . doi: 10.1016/j.socscimed.2005.07.020

8. Wade TJ, Pevalin DJ (2004) Marital transitions and mental health. J Health Soc Behav 45:155-170 . doi: 10.1177/002214650404500203

9. Amato PR (2000) The Consequences of Divorce for Adults and Children. J Marriage Fam 62:1269-1287 . doi: 10.1111/j.1741-3737.2000.01269.x 
1 10. Kalmijn M (2017) The Ambiguous Link between Marriage and Health: A Dynamic Reanalysis of Loss and Gain Effects. Soc Forces 95:1607-1636 . doi: 10.1093/sf/sox015

11. Hemstrom O (1996) Is Marriage Dissolution Linked to Differences in Mortality Risks for Men and Women? J Marriage Fam 58:366-78

12. Bulloch AG, Williams JV, Lavorato DH, Patten SB (2009) The relationship between major depression and marital disruption is bidirectional. Depress Anxiety 26:11721177 . doi: $10.1002 /$ da. 20618

13. Kessler RC, Walters EE, Forthofer MS (1998) The social consequences of psychiatric disorders, III: probability of marital stability. Am J Psychiatry 155:1092-1096 . doi: 10.1176/ajp.155.8.1092

14. Lund R, Holstein BE, Osler M (2004) Marital history from age 15 to 40 years and subsequent 10-year mortality: a longitudinal study of Danish males born in 1953. Int J Epidemiol 33:389-397 . doi: 10.1093/ije/dyh065

15. Murray JE (2000) Marital protection and marital selection: evidence from a historicalprospective sample of American men. Demography 37:511-521

16. Metsä-Simola N, Martikainen P (2013) Divorce and changes in the prevalence of psychotropic medication use: A register-based longitudinal study among middle-aged Finns. Soc Sci Med 94:71-80 . doi: 10.1016/j.socscimed.2013.06.027

17. Mojtabai R, Stuart EA, Hwang I, et al (2017) Long-term effects of mental disorders on marital outcomes in the National Comorbidity Survey ten-year follow-up. Soc Psychiatry Psychiatr Epidemiol 52:1217-1226 . doi: 10.1007/s00127-017-1373-1

18. Butterworth P, Rodgers B (2008) Mental health problems and marital disruption: is it the combination of husbands and wives' mental health problems that predicts later 
divorce? Soc Psychiatry Psychiatr Epidemiol 43:758-763 . doi: 10.1007/s00127-0080366-5

19. Idstad M, Torvik FA, Borren I, et al (2015) Mental distress predicts divorce over 16 years: the HUNT study. BMC Public Health 15: . doi: 10.1186/s12889-015-1662-0

20. OECD (1982) The OECD List of Social Indicators. OECD, Paris

21. StataCorp (2009) Stata: Release 11. Statistical Software. StataCorp LP, College Station, Texas

22. Nihtilä E, Martikainen P (2008) Institutionalization of Older Adults After the Death of a Spouse. Am J Public Health 98:1228-1234 . doi: 10.2105/AJPH.2007.119271

23. Metsä-Simola N, Martikainen P (2013) The short-term and long-term effects of divorce on mortality risk in a large Finnish cohort, 1990-2003. Popul Stud 67:97-110 . doi: 10.1080/00324728.2012.746386

24. Waite LJ, Luo Y, Lewin AC (2009) Marital happiness and marital stability: Consequences for psychological well-being. Soc Sci Res 38:201-212 . doi: 10.1016/j.ssresearch.2008.07.001

25. Willitts M, Benzeval M, Stansfeld S (2004) Partnership history and mental health over time. J Epidemiol Community Health 58:53-58

26. Wilson SE, Waddoups SL (2002) Good marriages gone bad: Health mismatches as a cause of later-life marital dissolution. Popul Res Policy Rev 21:505-533 . doi: 10.1023/A:1022990517611

27. Burman B, Margolin G (1992) Analysis of the association between marital relationships and health problems: an interactional perspective. Psychol Bull 112:39_ 63

28. Lillard LA, Panis CW (1996) Marital status and mortality: the role of health. Demography 33:313-327 
1 29. Halleröd B, Gustafsson J-E (2011) A longitudinal analysis of the relationship between changes in socio-economic status and changes in health. Soc Sci Med 72:116-123 . doi: 10.1016/j.socscimed.2010.09.036

30. Lahelma E, Martikainen P, Laaksonen M, Aittomaki A (2004) Pathways between socioeconomic determinants of health. J Epidemiol Community Health 58:327-332 . doi: 10.1136/jech.2003.011148

31. Jalovaara M (2013) Socioeconomic Resources and the Dissolution of Cohabitations and Marriages. Eur J Popul Rev Eur Démographie 29: . doi: 10.1007/s10680-0129280-3

32. Lyngstad T, Jalovaara M (2010) A review of the antecedents of union dissolution. Demogr Res 23:257-292 . doi: 10.4054/DemRes.2010.23.10

33. Gerstel N, Riessman CK, Rosenfield S (1985) Explaining the Symptomatology of Separated and Divorced Women and Men: The Role of Material Conditions and Social Networks. Soc Forces 64:84-101 . doi: 10.1093/sf/64.1.84

34. Lee S, Cho E, Grodstein F, et al (2005) Effects of marital transitions on changes in dietary and other health behaviours in US women. Int J Epidemiol 34:69-78 . doi: 10.1093/ije/dyh258

35. Umberson D (1992) Gender, marital status and the social control of health behavior. Soc Sci Med 1982 34:907-917

36. Poortman A-R (2000) Sex Differences in the Economic Consequences of Separation: A Panel Study of the Netherlands. Eur Sociol Rev 16:367-383

37. Pienta AM, Hayward MD, Jenkins KR (2000) Health Consequences of Marriage for the Retirement Years. J Fam Issues 21:559-586 . doi: 10.1177/019251300021005003 
1 38. Garvin V, Kalter N, Hansell J (1993) Divorced women: individual differences in stressors, mediating factors, and adjustment outcome. Am J Orthopsychiatry 63:232240

39. Alonso J, Angermeyer MC, Bernert S, et al (2004) Prevalence of mental disorders in Europe: results from the European Study of the Epidemiology of Mental Disorders (ESEMeD) project. Acta Psychiatr Scand Suppl 21-27 . doi: 10.1111/j.16000047.2004.00327.x

40. Jacobi F, Wittchen H-U, Holting C, et al (2004) Prevalence, co-morbidity and correlates of mental disorders in the general population: results from the German Health Interview and Examination Survey (GHS). Psychol Med 34:597-611 . doi: $10.1017 / \mathrm{S} 0033291703001399$

41. de Graaf R, Bijl RV, Smit F, et al (2002) Risk factors for 12-month comorbidity of mood, anxiety, and substance use disorders: findings from the Netherlands Mental Health Survey and Incidence Study. Am J Psychiatry 159:620-629 . doi: 10.1176/appi.ajp.159.4.620

42. Pirkola SP, Isometsä E, Suvisaari J, et al (2005) DSM-IV mood-, anxiety- and alcohol use disorders and their comorbidity in the Finnish general population. Soc Psychiatry Psychiatr Epidemiol 40:1-10 . doi: 10.1007/s00127-005-0848-7

43. Boschloo L, Vogelzangs N, Smit JH, et al (2011) Comorbidity and risk indicators for alcohol use disorders among persons with anxiety and/or depressive disorders: findings from the Netherlands Study of Depression and Anxiety (NESDA). J Affect Disord 131:233-242 . doi: 10.1016/j.jad.2010.12.014

44. Amato PR, Previti D (2003) People's Reasons for Divorcing: Gender, Social Class, the Life Course, and Adjustment. J Fam Issues 24:602-626 . doi: $10.1177 / 0192513 X 03254507$ 
1 45. Collins RL, Ellickson PL, Klein DJ (2007) The role of substance use in young adult divorce. Addict Abingdon Engl 102:786-794 . doi: 10.1111/j.13600443.2007.01803.x

46. Joutsenniemi K, Moustgaard H, Koskinen S, et al (2011) Psychiatric comorbidity in couples: a longitudinal study of 202,959 married and cohabiting individuals. Soc Psychiatry Psychiatr Epidemiol 46:623-633 . doi: 10.1007/s00127-010-0228-9

47. Linjakumpu T, Hartikainen S, Klaukka T, et al (2002) Psychotropics among the home-dwelling elderly--increasing trends. Int J Geriatr Psychiatry 17:874-883 . doi: 10.1002/gps.712

48. Desplenter F, Caenen C, Meelberghs J, et al (2011) Change in psychotropic drug use among community-dwelling people aged 75 years and older in Finland: repeated cross-sectional population studies. Int Psychogeriatr 23:1278-1284 . doi: $10.1017 / \mathrm{S} 1041610211000718$

49. Hämäläinen J, Isometsä E, Laukkala T, et al (2004) Use of health services for major depressive episode in Finland. J Affect Disord 79:105-112 . doi: 10.1016/S01650327(02)00342-7 
1 Fig. 1 Age-adjusted hazard ratio (HR, 95\% CI) of divorce by time since psychiatric morbidity

2 (PM) incidence and gender, married Finnish couples aged 40 to 64

3

4 
1 Table 1. Characteristics of the study cohort, married Finnish couples aged 40 to 64

$\begin{array}{lrrrr} & \text { N } & \text { Divorces } & \begin{array}{r}\text { Mean age, } \\ \text { husband }\end{array} & \begin{array}{r}\text { Mean age, } \\ \text { wife }\end{array} \\ \text { ALL } & 96222 & 7932 & 51.4 & 49.5 \\ \begin{array}{l}\text { Psychiatric morbidity } \\ \quad \text { None }\end{array} & 72231 & 5657 & 51.2 & 49.4 \\ \quad \text { Husband only } & 7667 & 852 & 51.7 & 49.8 \\ \quad \text { Wife only } & 12849 & 1153 & 51.7 & 49.8 \\ \quad \text { Both spouses } & 2475 & 270 & 52.3 & 50.5\end{array}$


Table 2. Adjusted hazard ratio of divorce (HR) by covariates, married Finnish couples aged 40 to 64

\begin{tabular}{|c|c|c|c|c|c|c|}
\hline & Distribution $^{\text {a }}$ & $\begin{array}{l}\text { Model 1: } \\
\text { Age- } \\
\text { adjusted }\end{array}$ & & $\begin{array}{l}\text { Model 2: Model } 1 \\
\text { +Psychiatric } \\
\text { morbidity }\end{array}$ & $\begin{array}{l}\text { Model 3: All } \\
\text { covariates }\end{array}$ & \\
\hline & $\%$ & $\mathrm{HR}$ & $95 \% \mathrm{Cl}$ & $\mathrm{HR}$ & $\mathrm{HR}$ & $95 \% \mathrm{Cl}$ \\
\hline \multicolumn{7}{|l|}{$\begin{array}{l}\text { Psychiatric } \\
\text { morbidity }\end{array}$} \\
\hline Husband only & 8.0 & 2.33 & $(2.13,2.54)$ & - & 2.17 & $(2.00,2.37)$ \\
\hline Wife only & 13.4 & 1.84 & $(1.71,1.98)$ & - & 1.79 & $(1.66,1.93)$ \\
\hline Both spouses & 2.6 & 2.98 & $(2.53,3.51)$ & - & 2.58 & $(2.19,3.04)$ \\
\hline \multicolumn{7}{|l|}{ Male education } \\
\hline Tertiary & 30.5 & 1.00 & & 1.00 & 1.00 & \\
\hline Intermediary & 31.4 & 1.06 & $(1.00,1.12)$ & 1.06 & 1.04 & $(0.97,1.11)$ \\
\hline Basic & 38.0 & 1.09 & $(1.03,1.15)$ & 1.09 & 1.02 & $(0.95,1.10)$ \\
\hline \multicolumn{7}{|l|}{ Female education } \\
\hline Tertiary & 28.8 & 1.00 & & 1.00 & 1.00 & \\
\hline Intermediary & 35.3 & 0.94 & $(0.89,1.00)$ & 0.94 & 0.89 & $(0.84,0.95)$ \\
\hline Basic or less & 35.9 & 1.07 & $(1.00,1.12)$ & 1.06 & 0.95 & $(0.88,1.02)$ \\
\hline \multicolumn{7}{|l|}{ M ale social class } \\
\hline Upper non-manual & 21.1 & 1.00 & & 1.00 & 1.00 & \\
\hline Lower non-manual & 19.5 & 1.01 & $(0.94,1.08)$ & 1.01 & 0.99 & $(0.91,1.06)$ \\
\hline Manual & 39.2 & 1.07 & $(1.01,1.14)$ & 1.07 & 0.96 & $(0.88,1.04)$ \\
\hline Other & 20.2 & 0.94 & $(0.88,1.01)$ & 0.94 & 0.86 & $(0.79,0.94)$ \\
\hline \multicolumn{7}{|l|}{ Female social class } \\
\hline Upper non-manual & 14.6 & 1.00 & & 1.00 & 1.00 & \\
\hline Lower non-manual & 46.6 & 0.92 & $(0.86,0.98)$ & 0.92 & 0.93 & $(0.86,1.00)$ \\
\hline Manual & 24.2 & 1.09 & $(1.01,1.17)$ & 1.09 & 1.01 & $(0.91,1.10)$ \\
\hline Other & 14.6 & 0.94 & $(0.86,1.02)$ & 0.94 & 0.91 & $(0.83,1.00)$ \\
\hline
\end{tabular}


Male main activity

Employed

74.0

Unemployed

7.9

Retired

15.1

Other

2.9

Female main activity

Employed

Unemployed

74.9

Retired

9.0

Other

\section{8}

Household income level

$$
\begin{aligned}
& \text { 5. quintile (highest) } \\
& \text { 4. quintile } \\
& \text { 3. quintile } \\
& \text { 2. quintile } \\
& \text { 1. quintile (lowest) }
\end{aligned}
$$

20.0

20.0

20.0

20.0

20.0

1.00

$\begin{array}{ll} & 1.00 \\ (1.46,1.73) & 1.55\end{array}$

1.00

1.59

$(1.46,1.73)$

$(1.90,2.18)$

1.28

1.69

$(1.17,1.41)$

2.03

$(1.93,2.38)$

1.92
2.11

$(1.58,1.82)$

1.80

$(1.61,2.01)$

Housing tenure

Home-owner

Tenant or other

88.9

11.1

1.00

1.36

1.00

1.00

$(1.26,1.46) \quad 1.34$

1.10

$(1.65,1.91)$

1.71

1.41

$(1.04,1.20)$

$(1.28,1.53)$

1.39

$(1.30,1.52)$

1.20

$(1.09,1.32)$

1.00

0.99

1.00

1.00

0.96

0.99

1.00

$(0.89,1.04)$

1.08

0.99

$(0.92,1.07)$

1.18

$(1.10,1.27)$

1.18

$(0.92,1.09)$

$(1.42,1.62)$

1.51

$(1.05,1.25)$

1.00

1.81

$(1.71,1.92)$

1.00

1.15

Co-resident children under 18

None

58.4

1.00

1.79

1.00

1.59

$(1.50,1.69)$

At least 1

41.7

1.04

$(1.71,1.92)$

1.00

1.00

Union duration

$0-4$ years
$5-9$ years
10 years or more

2.8

3.3

1.00

0.73

$(0.62,0.87)$
$(0.33,0.44)$

1.05

1.00

$(0.94,1.06)$

93.9

0.38

1.00

1.00

0.76

$(0.65,0.90)$

$\begin{array}{ll}0.39 & 0.50\end{array}$

$(0.43,0.57)$

${ }^{a}$ Psychiatric morbidity during the follow-up, other covariate distributions at baseline $\quad{ }^{\mathrm{b}}$ Date of psychiatric morbidity incidence with a 6-month lag 
Table 3. Adjusted hazard ratio of divorce (HR) by measure of psychiatric morbidity, married Finnish couples aged 40 to $64^{1}$

\begin{tabular}{|c|c|c|c|c|c|}
\hline & Distribution & $\begin{array}{l}\text { Model 1: } \\
\text { Age-adjusted }\end{array}$ & & $\begin{array}{l}\text { Model } 2 \text { : } \\
\text { All covariates }\end{array}$ & \\
\hline Psychiatric hospitalization & $\%$ & $H R$ & $95 \% \mathrm{Cl}$ & $H R$ & $95 \% \mathrm{Cl}$ \\
\hline None & 97.7 & 1.00 & & 1.00 & \\
\hline Husband only & 0.9 & 3.50 & $(3.01,4.07)$ & 2.81 & $(2.41,3.27)$ \\
\hline Wife only & 1.3 & 2.78 & $(2.42,3.19)$ & 2.18 & $(1.90,2.51)$ \\
\hline Both spouses & 0.04 & 4.02 & $(1.92,8.45)$ & 2.27 & $(1.08,4.77)$ \\
\hline \multicolumn{6}{|l|}{ Psychotropic medication } \\
\hline None & 76.2 & 1.00 & & 1.00 & \\
\hline Husband only & 8.0 & 2.20 & $(2.04,2.39)$ & 2.02 & $(1.87,2.19)$ \\
\hline Wife only & 13.3 & 1.82 & $(1.70,1.95)$ & 1.75 & $(1.63,1.87)$ \\
\hline Both spouses & 2.6 & 3.03 & $(2.62,3.51)$ & 2.60 & $(2.24,3.01)$ \\
\hline
\end{tabular}

${ }^{1}$ Note that these figures describe results that we would obtain if we only used one measure of psychiatric morbidity (hospital in-patient care or psychotropic medication) throughout the study: Unhealthy couples were excluded at baseline, and the exclusion is based on the chosen measure of psychiatric morbidity. Any individual with hospital in-patient care may also have psychotropic medication purchases and thus be identified with psychiatric morbidity based on both measures. 